\title{
AVALIAÇÃO DO TEOR DE METAIS PESADOS E DE PARÂMETROS FÍSICO-QUÍMICOS DA ÁGUA E SEDIMENTO DO LAGO BONSUCESSO, JATAÍ - GO
}

Rafael Oliveira Martins ${ }^{1}$, Carlos Henrique Hoff Brait $^{2}$, Francismário Ferreira dos Santos ${ }^{3}$

(1 - Universidade federal de Goiás -Regional Jataí, Discente do curso Química, rafaels144@hotmail.com; 2 - Pesquisador e Diretor do Laboratório Exata, carlosbrait@labexata.com.br; 3 - Universidade Federal de Goiás, Professor Associado da Universidade Federal de Goiás, marinhofsantos@ hotmail.com)

Resumo: Este trabalho teve como objetivo avaliar o teor de metais pesados $(\mathrm{Al}, \mathrm{Fe}, \mathrm{Cu}, \mathrm{Pb}$, $\mathrm{Zn}, \mathrm{Mn}, \mathrm{Cr}, \mathrm{Ni}, \mathrm{Cd}, \mathrm{As}, \mathrm{Hg}$ ) em água e sedimento e algumas propriedades físico-químicas $(\mathrm{pH}$, oxigênio dissolvido $(\mathrm{OD})$, fósforo total $(\mathrm{P})$, condutividade elétrica(CE), turbidez (TURB), dureza total (DT), total de sólidos dissolvidos (TDS), $\mathrm{NaCl}, \mathrm{NO}_{3}{ }^{-}, \mathrm{NO}_{2}{ }^{-}$. Adicionalmente, foi feito a caracterização do sedimento (substância húmica (SH), matéria orgânica (MO) e capacidade de troca catiônica (CTC). Os dados dos parâmetros físicoquímicos classificam as águas do lago Bonsucesso como de classe 3, segundo resolução CONAMA n. 357-2005. Apenas o ponto 2 apresentou baixa concentração de MO. Concentrações maiores que $10 \%$ já indica uma capacidade deste reter poluentes orgânicos e inorgânicos. $\mathrm{O}$ pH do sedimento apresentou características ácidas, o que pode facilitar a liberação de íons complexados para o meio ambiente. As análises de metais pesados no sedimento revelaram a presença de Cádmio, Cromo, Cobre e Zinco em concentrações acima dos níveis 1 ou 2 da resolução CONAMA 454/2012, evidenciando o acúmulo no sedimento do lago. Na água, os metais Alumínio e Cobre apresentaram concentrações acima do limite permitido pela Resolução CONAMA n.357/2005, enquanto que os metais Arsênio e Mercúrio apenas nos pontos 1, 6, 8 e 1, 6 respectivamente.

Artigo recebido para publicação em 20 de Novembro de 2017

Artigo aprovado para publicação em 24 de Dezembro de 2017 


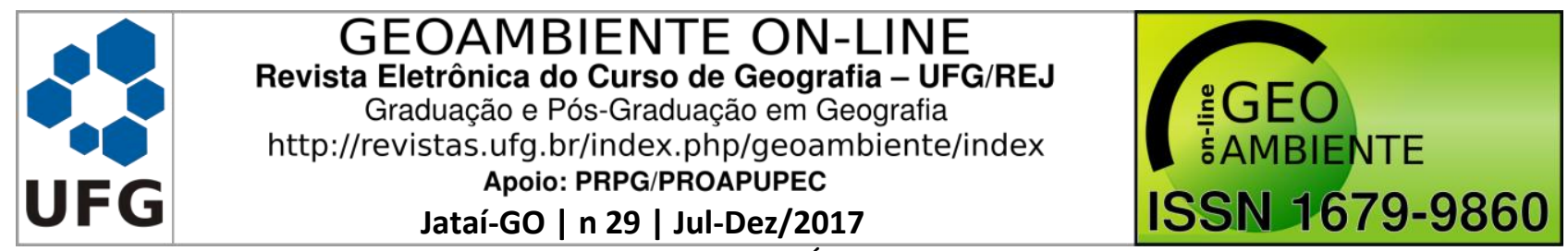

Palavras chave: Metais pesados, Sedimento, Água, Lago Bonsucesso, Parâmetros FísicoQuímicos

\title{
EVALUATION OF THE CONTENT OF HEAVY METALS AND PHYSICAL- CHEMICAL PARAMETERS OF WATER AND SEDIMENT OF LAKE BONSUCESSO, JATAÍ - GO
}

\begin{abstract}
This work aimed to evaluate the content of heavy metals (Al, $\mathrm{Fe}, \mathrm{Cu}, \mathrm{Pb}, \mathrm{Zn}, \mathrm{Mn}$, $\mathrm{Cr}, \mathrm{Ni}, \mathrm{Cd}, \mathrm{As}, \mathrm{Hg}$ ) in water and sediment and some physicochemical properties ( $\mathrm{pH}$, dissolveld oxigen (OD), total phosphorus (P), electric conductivity (CE), turbidity (TURB, hardness (TD), total dissolved solids (TDS), $\mathrm{NaCl}, \mathrm{NO}_{3}{ }^{-}, \mathrm{NO}_{2}{ }^{-}$). In addition, the sediment characterization (humic substance, organic matter (OM) and cation exchange capacity (CTC) was made. The data of the physicochemical parameters classify the waters of Lake Bonsucesso as class 3, according to CONAMA resolution n.357/2005. The $\mathrm{pH}$ of the sediment presented acidic characteristics, which may facilitate the release of complexed ions to the environment. The presence of cadmium, chromium, copper and zinc in concentrations above levels 1 or 2 of CONAMA resolution 454/2012, evidenced the accumulation in the sediment of the lake. In the water, the metals Aluminum and Copper presented concentrations above the limit allowed by CONAMA Resolution 357/2005, while the metals Arsenic and Mercury only at points $1,6,8$ and 1,6 , respectively.
\end{abstract}

Keywords: Heavy Metals, Sediment, Water, Bonsucesso Lake, Physical-Chemical Parameters

\section{EVALUACIÓN DEL CONTENIDO METALES PESADOS Y PARÁMETROS FÍSICO-QUÍMICOS DEL AGUA Y SEDIMIENTO DEL LAGO BONSUCESSO, JATAÍ - GO}

Resumen: Este trabajo tuvo como objetivo evaluar el contenido de metales pesados (Al, Fe, $\mathrm{Cu}, \mathrm{Pb}, \mathrm{Zn}, \mathrm{Mn}, \mathrm{Cr}, \mathrm{Ni}, \mathrm{Cd}, \mathrm{As}, \mathrm{Hg}$ ) en agua y sedimento y algunas propiedades fisicoquímicas ( $\mathrm{pH}$, oxígeno disuelto $(\mathrm{OD})$, fósforo total $(\mathrm{P})$, conductividad eléctrica $(\mathrm{CE})$, turbidez (TURB), total de sólidos disueltos (TDS), $\mathrm{NaCl}, \mathrm{NO}_{3}{ }^{-}, \mathrm{NO}_{2}{ }^{-}$. Adicionalmente, se hizo la caracterización del sedimento (sustancia húmica $(\mathrm{SH})$, materia orgánica $(\mathrm{MO})$ y capacidad de intercambio catiónico (CTC). Los datos de los parámetros físico-químicos 


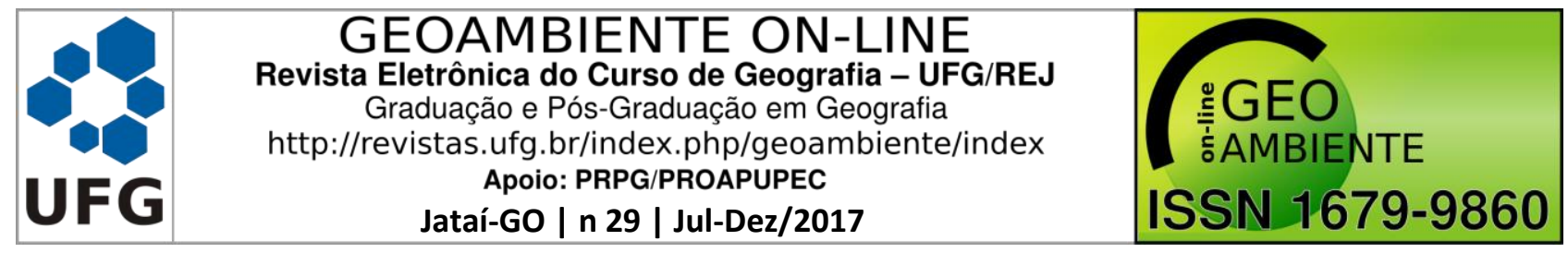

clasifican las aguas del lago Bonsucesso como de clase 3, según resolución CONAMA n. 357/2005. Sólo el punto 2 presentó una baja concentración de MO. Concentraciones mayores que el $10 \%$ ya indica una capacidad para conservar los contaminantes orgánicos e inorgánicos. El pH del sedimento presenta características ácidas, lo que puede facilitar la liberación de iones complejos para el medio ambiente. Los análisis de metales pesados en el sedimento revelaron la presencia de Cadmio, Cromo, Cobre y Zinc en concentraciones superiores a los niveles 1 o 2 de la resolución CONAMA 454/2012, evidenciando la acumulación en el sedimento del lago. En el agua, los metales Aluminio y Cobre presentaron concentraciones por encima del límite permitido por la Resolución CONAMA n.357/2005, mientras que los metales Arsénico y Mercurio sólo en los puntos 1, 6, 8 y 1, 6 respectivamente.

Palabras clave: Metales pesados, Sedimento, Agua, Lago Bonsucesso, Parámetros FísicoQuímicos

\section{INTRODUÇÃO}

No atual cenário em que se encontra a sociedade, a água se tornou um recurso indispensável em diversas atividades humanas, tais como atividades industriais, agrícolas, abastecimento público, entre outras. Embora essas atividades sejam importantes, elas podem gerar sérios problemas ambientais, como a poluição de corpos hídricos através de efluentes contendo diversos resíduos químicos. Dentre os diversos recursos naturais, a água é considerada renovável, porém, sua qualidade vem se deteriorando em função de diversas atividades de produção, seja ela agrícola, industrial, doméstica, etc, o que poderá inviabilizar seu uso, por exemplo, em atividades de produção de alimentos (DUARTE et al, 2000).

Os resíduos químicos gerados pelas atividades domésticas, especialmente o esgoto doméstico, tem sido considerado o principal responsável pela deterioração da qualidade da água. Entretanto, não se deve deixar de mencionar a grande contribuição das atividades agrícolas que utilizam milhões de litros de insumos agrícolas como pesticidas e fertilizantes na produção de alimento, insumos estes que contêm diferentes espécies químicas poluentes em suas formulações (ALVES et al., 2010). 


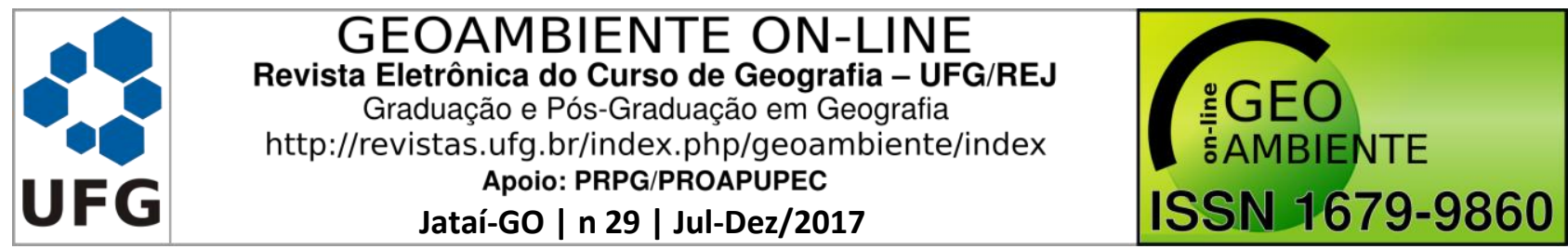

Os metais podem ser encontrados naturalmente na composição de algumas rochas na superfície terrestre, entretanto, no ambiente aquático, os metais podem ser incorporados por processos naturais como o intemperismo e atividades antropogênicas. Essas espécies, devido não se degradarem quimicamente ou biologicamente, são consideradas uma classe especial de poluente e de acordo com sua concentração, no ambiente aquático e características físicoquímicas da água, podem gerar graves alterações no ambiente (ALVES et al., 2010), por exemplo, causar uma série de danos a fauna e flora aquática. Devido ao aumento da concentração destes no ambiente, a poluição por metais pesados vem ganhando destaque nas últimas décadas (CONAMA, 2012).

As atividades agrícolas constituem uma das mais importantes fontes não pontuais de poluição por metais. Neste setor se destaca o uso de fertilizantes e agroquímicos, produtos estes que possuem resíduos de metais pesados em sua composição ( $\mathrm{Pb}, \mathrm{Al}, \mathrm{Cd}, \mathrm{Cu}, \mathrm{Fe}, \mathrm{Zn}$, $\mathrm{Ni}, \mathrm{Mn}, \mathrm{Cr}$ ). Quando aplicados em cultivos, esses produtos podem atingir corpos hídricos através da água de chuva ou mesmo de irrigação, ou indiretamente através da percolação no solo, chegando aos lençóis freáticos (ARIAS, 2007).

Uma vez no ambiente aquático, os metais também podem interagir com o sedimento por meio de interações físicas e químicas e, neste caso, fixarem definitivamente ou parcialmente no sedimento (ARIAS, 2007. Os sedimentos de ambientes aquáticos constituem uma fase mineralógica com partículas de tamanhos, formas e composição química distintas. Esses materiais ao longo dos anos vão se acumulando nos fundos dos lagos, rios e oceanos. Como são importantes depositários de substâncias, inclusive metais pesados, os sedimentos refletem as variações históricas da intensidade de poluição produzida na bacia (MARGALEF, 1983. Além disso, os sedimentos não podem ser mais considerados como um reservatório ou ambiente de deposição de espécies químicas, mas como um compartimento aquático ativo que desempenha um papel fundamental na redistribuição dessas espécies à biota aquática. Os fenômenos de acúmulo e de redis-posição de espécies nos sedimentos os qualificam como de extrema importância em estudos de impacto ambiental, pois registram em caráter mais permanente os efeitos de contaminação. Para se ter uma idéia, estima-se que menos de $1 \%$ das substâncias que atingem o sistema aquático são dissolvidas em água, consequentemente, mais de $99 \%$ são estocadas no compartimento sedimentar. Contudo, diversos processos bióticos e abióticos podem remobilizar tais espécies, constituindo-se em fontes de poluição secundárias 


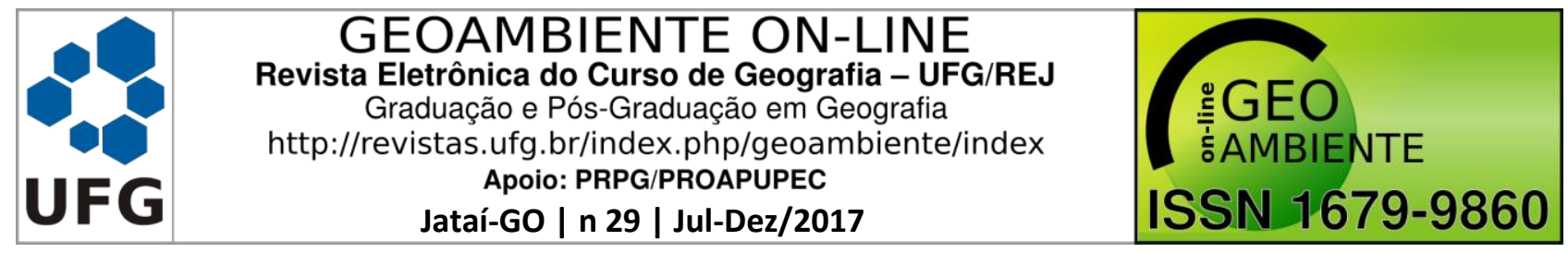

afetando a qualidade da água e originando bioacumulação e trocas de transferência na cadeia trófica (JACKSON, 1967).

A literatura científica brasileira contribui muito pouco com pesquisas em nível mundial e nacional em termos da presença de poluentes nos recursos d’água, especialmente em relação à pesquisa no âmbito ambiental com sedimentos (MARGALEF, 1983); MOURAL, 2013). Estudos recentes com metais pesados e outras espécies poluentes tem sido realizados no Brasil. Em um estudo realizado nas águas do Ribeirão Samambaia, em CatalãoGO, revelaram a presença de cádmio, chumbo e cromo em concentrações acima do limite máximo permito pelo CONAMA. Já para as quantificações dos metais nas amostras de sedimento apenas o cromo apresentou concentração acima do permitido. De acordo com os autores, os resultados indicaram que as atividades antrópicas contribuíram com efeitos negativos para biota local e aos seres humanos.

Em razão da importância da qualidade de água, dos problemas a saúde que pode ser causado pela ingestão de água contaminada por metais pesados provenientes de agroquímicos e outras fontes, este trabalho teve como objetivo avaliar a presença de metais pesados potencialmente tóxicos e as propriedades físico-químicas da água e sedimentos do lago Bonsucesso da cidade de Jataí-GO.

\section{Histórico e Localização do lago Bonsucesso}

A cidade de Jataí está localizada no sudoeste de Goiás, é considerada uma das cidades mais importantes da região fazendo divisa com os municípios de Caiapônia ao norte, Rio Verde a leste, Aparecida do Rio Doce ao sudeste; Caçú e Itarumã ao sul, Serranópolis a sudoeste, Mineiros ao oeste e Perolândia a noroeste. A cidade fica a uma distância de $327 \mathrm{Km}$ de sua capital (Goiânia). O principal rio que abastece a cidade é o Rio Claro, que também é utilizado para abastecimento público de água nas cidades próximas de jataí. (SILVA, 2007).

O lago Bonsucesso é um dos vários pontos turísticos que se encontra na cidade de Jataí - GO e faz parte do Complexo Turístico do Vale do Paraíso. Desde sua construção em 2000 teve o objetivo de oferecer aos moradores da cidade e região mais uma opção de lazer como atividades de pesca, esportes. Com o passar dos anos, essa região atraiu olhares de empreendedores que tomaram a iniciativa de tornar este o cartão postal mais atrativo da 


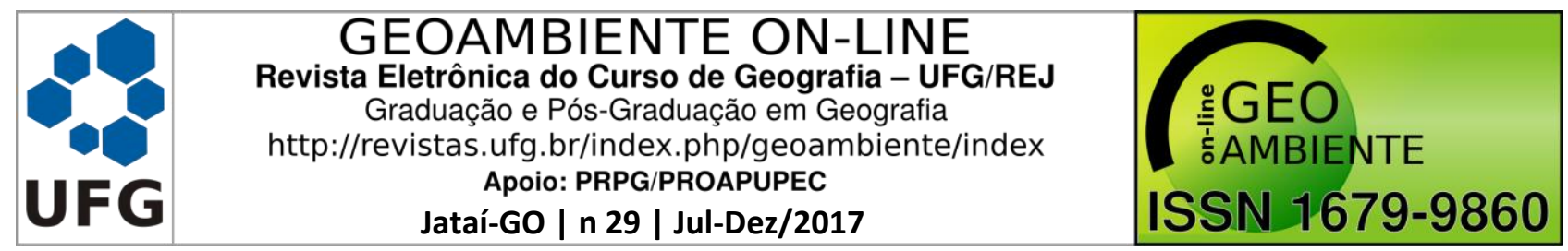

cidade sendo então criado o parque aquático conhecido como Thermas Park Jatahy e o conhecido Hotel Thermas Bonsucesso.

Este complexo turístico está localizado na BR 158, a uma distância de $10 \mathrm{~km}$ da cidade de jataí. O Lago Bonsucesso (figura 1) localiza-se entre as coordenadas de $416351 \mathrm{~m}$ a $430610 \mathrm{~m}$ de latitude Leste e $8026938 \mathrm{~m}$ a $8047852 \mathrm{~m}$ de longitude Norte do fuso UTM na folha de Jataí (SE-22-V-D-V-3-NE). Mesmo com o seu grande tamanho, ainda é considerado de porte pequeno, possuindo cerca de 74 hectares e com aproximadamente 2.300 metros de extensão. A profundidade varia a cada ponto no lago, sendo essa variação de dois metros de profundidade, em média, a oito metros nas proximidades da barragem. O reservatório é abastecido pelo córrego Bonsucesso, que percorre toda bacia (SILVA, 2007).

Figura 1. Vista aérea do lago Bonsucesso no ano de 2013

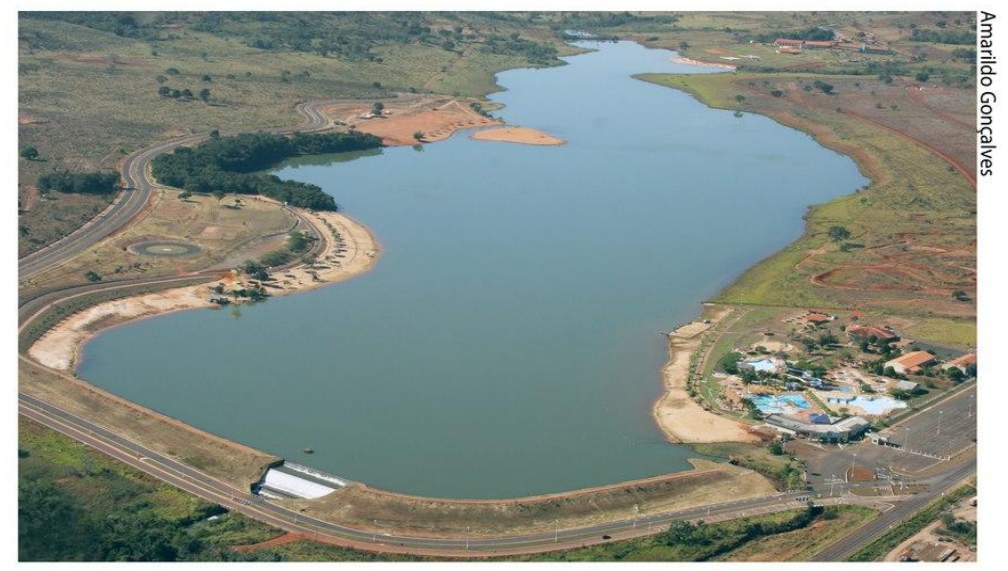

Fonte: Amarildo Gonçalves (2013)

Além das características sociais e políticas, a cidade de Jataí destaca-se ainda como uma região altamente produto de grãos como o milho e a soja, começando a se destacar também com a expansão da cultura de cana de açúcar.

\section{2 - MATERIAIS E MÉTODOS}

A coleta das amostras de água do lago Bonsucesso foi realizada em nove pontos (Figura 2). A coleta foi realizada considerando-se a vegetação ao redor do lago, área de lazer e o uso e ocupação do solo em dois períodos distintos, ou seja, período seco (24 de Setembro 


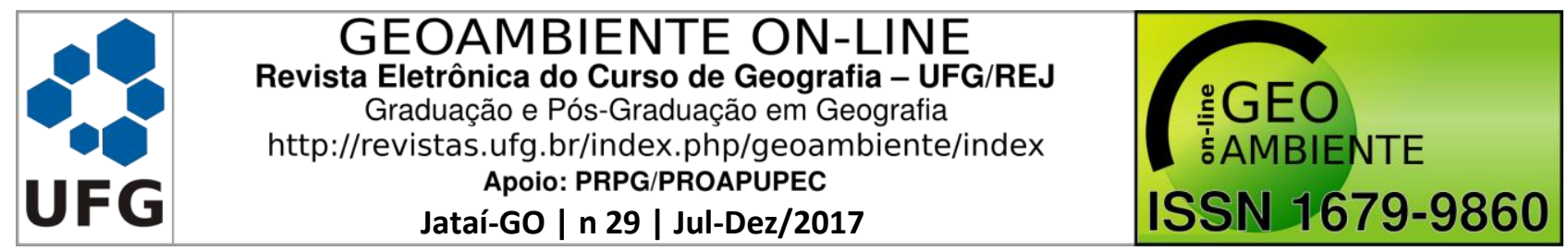

de 2016) e chuva (21 de Janeiro de 2017) que corresponde ao período de chuva, para fins de comparação. Os sedimentos foram coletados no mesmo ponto e data da coleta de água, ou seja, em janeiro de 2017. Os frascos para coleta de água foram previamente descontaminados no laboratório, em banho com solução de $\mathrm{HNO}_{3}$ diluído e no local de amostragem foram lavadas três vezes com a água do próprio (KASPER et al., 2014).

Para a coleta de sedimentos, foi utilizada a draga de Van Veen. Logo após a coleta, o sedimento foi armazenado em sacolas plásticas e deixado secar por cerca de um mês (FILIZOLA, 2006). Para a coleta da água, utilizaram-se frascos de polietileno. A determinação de metais totais em água e sedimento foi realizada por espectrometria de emissão atômica com plasma de argônio induzido (ICP-OES), Thermo Jarrel Ash, modelo IRIS/AP (APHA, 1998). A análise dos parâmetros físico-químicos (pH, OD, TDS, NaCl) dos nove pontos foi realizada in situ por meio de uma sonda multi-parâmetros (OAKLON PCD650). A determinação de $\mathrm{P}, \mathrm{DT}, \mathrm{TURB}, \mathrm{NO}_{3}, \mathrm{NO}_{2}$ foram realizadas em acordo com a metodologia descrita pela literatura (APHA, 1998).

Figura 2. Representação dos pontos utilizados para coleta

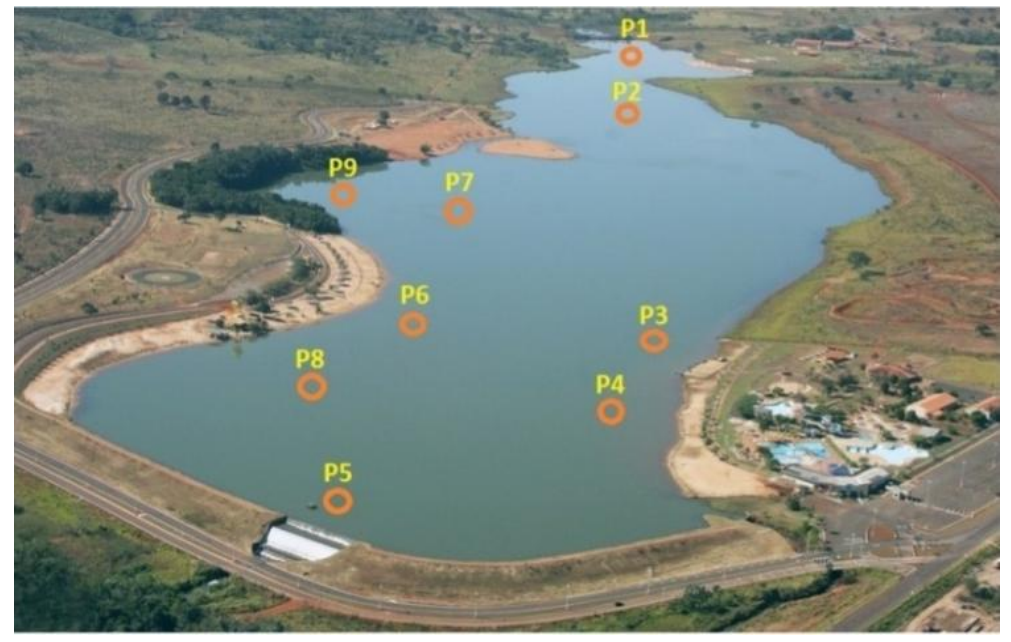

Fonte: Adaptado de Amarildo Gonçalves (2013)

\section{1 - Determinação de $\mathrm{pH}$ do Sedimento}




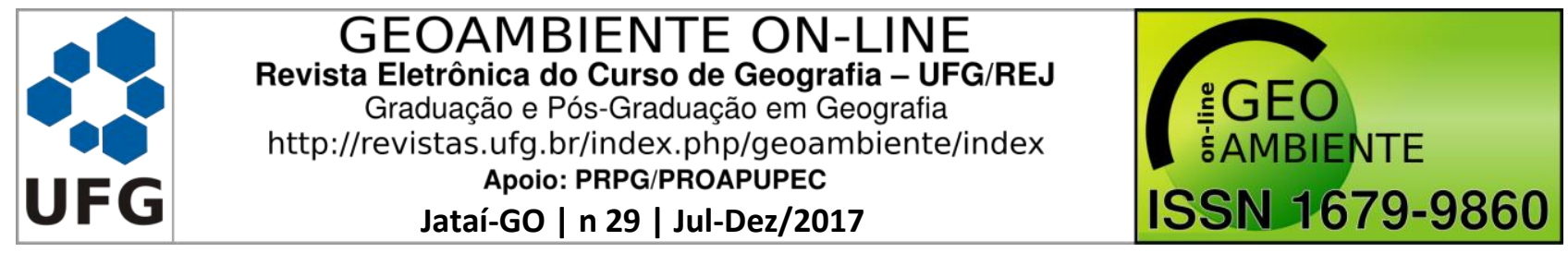

Para a determinação do $\mathrm{pH}$ do sedimento, em cada ponto de coleta, usou-se $10 \mathrm{~g}$ de amostra in natura em béquer de $100 \mathrm{~mL}$ e adição de $50 \mathrm{~mL}$ de solução de cloreto de cálcio 0,01 mol/L. Após 30 minutos, com ocasional agitação, o pH foi medido (ROSA, 2000).

\section{2 - Determinação da matéria orgânica do sedimento}

Para a determinação da matéria orgânica (MO) foi utilizado 1,0 g da massa triturada. Sendo assim, submeteu-se essa massa a queima em mufla numa temperatura de $500{ }^{0} \mathrm{C}$ por 4 horas e em seguida foi resfriada em ambiente livre de umidade. O cálculo da MO perdida por ignição se da por meio da diferença de massa (ROSA, 2000)

$\mathrm{MO}=(\mathrm{Ps}-\mathrm{Pm} / \mathrm{Ps}) \mathrm{x} 100$.

\section{3 - Determinação da Capacidade de Troca Catiônica (CTC) do sedimento}

Para determinação dos cátions metálicos totais trocáveis utilizou-se 2,50 g de amostra. Em seguida adicionou-se $25,00 \mathrm{~mL}$ de uma solução de ácido acético $1,00 \mathrm{~mol} \mathrm{~L}^{-1}$ e a suspensão foi agitada durante o período de 1 hora e então, mediu-se o pH, assim como o pH da solução de ácido acético. A determinação dos cátions metálicos totais trocáveis foi feita a partir da equação a seguir (JACKSON, 1967).

Equação de Cátions metálicos trocáveis $(\mathrm{cmolc} / \mathrm{kg})=[\mathrm{pH} 1-\mathrm{pH} 2]$ x 22

\subsection{Extração de Substâncias Húmicas $(\mathrm{SH})$ do Sedimento}

Inicialmente pesou-se 100,0 gramas de sedimentos previamente seco e peneirado para retirada de fragmentos de raízes. A extração da $\mathrm{SH}$ foi realizada com solução de $\mathrm{NaOH} 0,1$ mol L ${ }^{-1}$, na razao sedimento:solvente de 1:10 (m:v) em atmosfera inerte de $\mathrm{N}_{2}$, durante um período de 4 horas. Após este período, a mistura foi deixada em repouso por um período de 12 horas para decantação da SH . O material precipitado $(\mathrm{SH})$ foi separado por sifonação, ressuspendido com solução de $\mathrm{HCl}$ 6,0 mol. $\mathrm{L}^{-1}$ até $\mathrm{pH} 1$ para fracionamento do ácido fúlvico (AF) e ácido húmico (AH, precipitado). Após esse procedimento deixou-se a suspenção de $\mathrm{SH}$ e, repouso por um período de 16 horas para a precipitação do ácido húmico $(\mathrm{AH})$. 


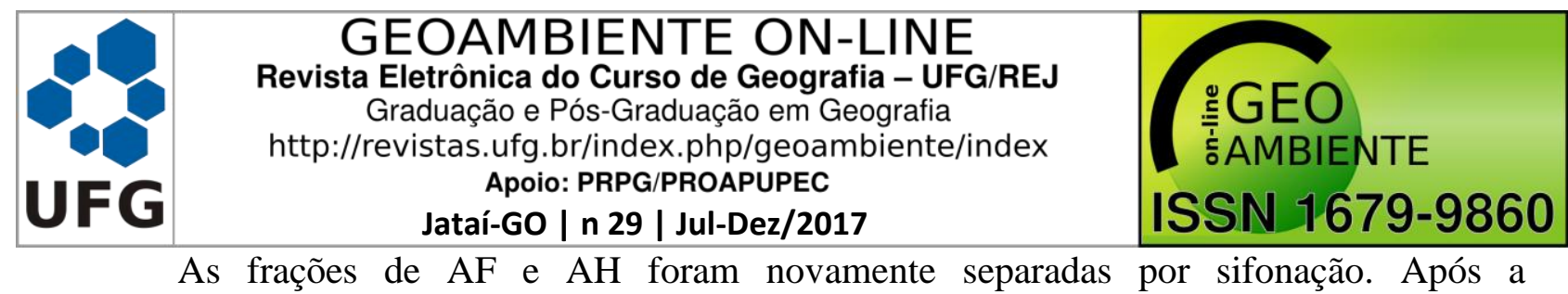

precipitação do $\mathrm{AH}$, centrifugou-se toda amostra para se recolher o $\mathrm{AH}$ e separar a suspenção de ácido fúlvico. Posteriormente foram adicionados ao precipitado de $\mathrm{AH}$ uma solução aquosa diluída de $\mathrm{HF}$ e $\mathrm{HCl}$ (200,0 mL de solução preparada pela adição de 5 mL de cada substância concentrada), e posterior adição de água destilada para um volume final de 1,0 litro. A solução de AH foi agitada durante 12 horas, deixada em repouso por 8 horas e sifonada para retirada do sobrenadante. A mistura então foi centrifugada até que atingisse um teor de cinzas recomendado. OBS: Este procedimento foi realizado até que o conteúdo de cinzas estivesse abaixo de $1 \%$.

\section{5 - Purificação do Ácido Húmico $(A H)$}

Após o procedimento 5.12.1, o AH foi transferido para membrana de diálise (Visking dialyses tube, $14 \mathrm{kDa}$ ) e dializado contra água destilada. Este procedimento foi realizado até teste negativo para cloretos com $\mathrm{AgNO}_{3}$. Este procedimento foi realizado durante 03 dias com a substituição da água da caixa até que a contutividade permanecesse constante, ou seja, igual a condutividade da água pura 0.5 a $3 \mu \mathrm{Scm}$ ( micro siemens). O AH dializado foi transferido para placas petri, seco em estufa na temperatura de $60{ }^{\circ} \mathrm{C}$, e posterior acondicionamento em frascos de polietileno para análise posteriores.

\section{3- RESULTADOS E DISCUSSÕES}

De acordo com a Tabela 1, considerando os valores mínimos e máximos para os períodos de seca e chuva, os valores da concentração de OD variaram entre 4,41mg/L e 12,20 mg/L, TURB entre 17,5 UNT e 26,2 UNT e pH 6,45 e 7,37 comparados aos valores permitidos segundo a resolução CONAMA N ${ }^{0}$ 357/2005, as águas do lago Bonsucesso se enquadram na classe 3. Segundo essa resolução, a concentração de OD, em qualquer amostra não deverá ser inferior a 4,0 mg.L ${ }^{-1}$; TURB até 100 UNT e o pH se encontrar na faixa entre 6 e 9.

Sendo assim, seguindo a Resolução 357 do CONAMA, ás águas do lago Bonsucesso podem ser utilizadas para a pesca e a recreação de moradores de cidade e região, e o seu consumo deve ser feito com um prévio tratamento convencional ou avançado. 


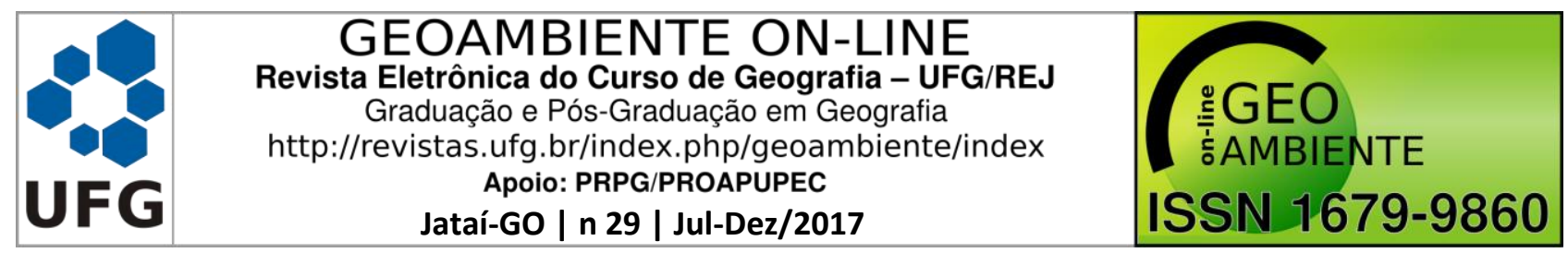

A partir da Tabela 1 pode-se aferir que os valores encontrados de $\mathrm{pH}$ para o lago Bonsucesso nas duas estações, se encontra de acordo com CONAMA n.357/2005 que estabelece um pH na faixa de 6,0 a 9,0 para águas naturais.

A CE é um parâmetro que é proporcional a concentração de íons presentes e dissociados em ambiente aquático. Foi observado que o maior de valor obtido para a estação da chuva $(29,41 \mu \mathrm{S})$ foi superior ao maior valor encontrado no período de seca $(24,60 \mu \mathrm{S})$. Esse comportamento é comum, pois a o período de chuva é onde ocorre o carreamento de partículas iônicas contidas no solo. Os valores encontrados nos dois períodos encontram-se em conformidade com a literatura para águas naturais, que estabelece o máximo de até 100 $\mu \mathrm{S} / \mathrm{cm}$ (LIMA, 20130).

Tabela 1- Parâmetros Físico-Químicos obtidos em estação seca e chuva

\begin{tabular}{|c|c|c|c|c|c|c|c|c|c|c|c|}
\hline \multirow[t]{2}{*}{ Período } & & \multicolumn{10}{|c|}{ Parâmetros Físico-químicos } \\
\hline & & $\mathrm{pH}$ & $\begin{array}{l}\mathrm{CE} \\
(\mu \mathrm{S})\end{array}$ & $\begin{array}{l}\text { OD } \\
(\mathrm{mg} / \mathrm{L})\end{array}$ & $\begin{array}{l}\mathrm{NaCl} \\
(\mathrm{mg} / \mathrm{L})\end{array}$ & $\begin{array}{l}\text { TDS } \\
\mathrm{mg} / \mathrm{L}\end{array}$ & $\begin{array}{l}\text { Alcali. } \\
\text { (mg/L) }\end{array}$ & $\begin{array}{l}\text { TURB } \\
\text { (UNT) }\end{array}$ & $\begin{array}{l}\text { P } \\
(\mathrm{mg} / \mathrm{L})\end{array}$ & $\begin{array}{l}\mathrm{NO}_{3}{ }^{2-} \\
(\mathrm{mg} / \mathrm{L})\end{array}$ & $\begin{array}{l}\mathrm{NO}_{2}^{-} \\
(\mathrm{mg} / \mathrm{L})\end{array}$ \\
\hline & P1 & 6,49 & 21,65 & 10,91 & 16,9 & 14,85 & 1,80 & 19,80 & 1,25 & $\mathrm{Nd}$ & $\mathrm{Nd}$ \\
\hline & P2 & 6,83 & 24,60 & 12,30 & 19,39 & 15,85 & 1,80 & 20,00 & 1,07 & $\mathrm{Nd}$ & $\mathrm{Nd}$ \\
\hline \multirow[t]{9}{*}{ Seco } & P3 & 7,15 & 24,20 & 12,12 & 19,44 & 14,78 & 1,80 & 18,50 & 1,02 & $\mathrm{Nd}$ & $\mathrm{Nd}$ \\
\hline & P4 & 7,37 & 24,29 & 12,14 & 19,45 & 13,50 & 1,80 & 19,20 & 0,96 & $\mathrm{Nd}$ & $\mathrm{Nd}$ \\
\hline & P5 & 7,16 & 24,39 & 12,20 & 19,56 & 13,35 & 1,80 & 17,50 & 0,89 & $\mathrm{Nd}$ & $\mathrm{Nd}$ \\
\hline & P6 & 7,14 & 24,35 & 12,20 & 19,71 & 13,48 & 1,80 & 20,20 & 0,64 & $\mathrm{Nd}$ & $\mathrm{Nd}$ \\
\hline & P7 & 7,09 & 24,33 & 12,16 & 19,47 & 13,59 & 1,80 & 20,40 & 0,87 & $\mathrm{Nd}$ & $\mathrm{Nd}$ \\
\hline & P8 & 7,18 & 24,31 & 12,13 & 19,77 & 13,69 & 1,80 & 19,50 & 0,92 & $\mathrm{Nd}$ & $\mathrm{Nd}$ \\
\hline & P9 & 7,11 & 24,13 & 12,04 & 19,29 & 13,79 & 1,80 & 19,80 & 0,77 & $\mathrm{Nd}$ & $\mathrm{Nd}$ \\
\hline & P1 & 6,65 & 28,48 & 5,35 & 21,43 & 86,10 & 1,75 & 23,20 & 1,15 & $\mathrm{Nd}$ & $\mathrm{Nd}$ \\
\hline & P2 & 6,94 & 29,41 & 4,88 & 22,49 & 86,00 & 1,75 & 26,20 & 0,72 & $\mathrm{Nd}$ & $\mathrm{Nd}$ \\
\hline \multirow[t]{5}{*}{ Chuva } & P3 & 6,84 & 27,97 & 4,70 & 22,14 & 127,30 & 1,75 & 24,50 & 0,95 & $\mathrm{Nd}$ & $\mathrm{Nd}$ \\
\hline & P4 & 6,65 & 24,18 & 4,82 & 21,07 & 110,50 & 1,75 & 24,90 & 1,05 & $\mathrm{Nd}$ & $\mathrm{Nd}$ \\
\hline & P5 & 6,56 & 25,20 & 4,76 & 20,94 & 112,50 & 1,75 & 25,20 & 0,86 & $\mathrm{Nd}$ & $\mathrm{Nd}$ \\
\hline & P6 & 6,45 & 25,45 & 5,42 & 21,05 & 113,00 & 1,75 & 26,20 & 0,92 & $\mathrm{Nd}$ & $\mathrm{Nd}$ \\
\hline & P7 & 6,65 & 25,59 & 4,66 & 21,16 & 115,10 & 1,75 & 23,90 & 0,90 & $\mathrm{Nd}$ & $\mathrm{Nd}$ \\
\hline
\end{tabular}




\begin{tabular}{|c|c|c|c|c|c|c|c|c|c|c|}
\hline \multirow{2}{*}{$\frac{\text { UFG }}{\mathrm{P} 8}$} & \multicolumn{7}{|c|}{$\begin{array}{c}\text { GEOAMBIENTE ON-LINE } \\
\text { Revista Eletrônica do Curso de Geografia - UFG/REJ } \\
\text { Graduação e Pós-Graduação em Geografia } \\
\text { http://revistas.ufg.br/index.php/geoambiente/index } \\
\text { Apoio: PRPG/PROAPUPEC } \\
\text { Jataí-GO | n 29 | Jul-Dez/2017 }\end{array}$} & \multicolumn{3}{|c|}{ ISSN 1679-9860 } \\
\hline & 6,77 & 25,73 & 4,41 & 21,22 & 110,40 & 1,75 & 24,90 & 0,87 & $\mathrm{Nd}$ & $\mathrm{Nd}$ \\
\hline P9 & 6,48 & 25,95 & 4,67 & 21,38 & 180,70 & 1,75 & 24,90 & 0,76 & $\mathrm{Nd}$ & $\mathrm{Nd}$ \\
\hline
\end{tabular}

Nd: Não detectado

A resolução do CONAMA 357/2005 estabelece um mínimo de $5 \mathrm{mg} \mathrm{L}^{-1}$ de OD, sendo que os valores obtidos in situ para o período seco estão de acordo com a legislação. Já para o período de chuva, nota-se que apenas os pontos 1 e 6 estão acima do valor recomendado. Uma das grandes causas do baixo teor de oxigênio dissolvido é o excesso de matéria orgânica podendo influenciar nesse decréscimo de $\mathrm{O}_{2}$ (ROCHA, 2003).

O teor de $\mathrm{NaCl}$ e TDS presentes em água influenciam na condutividade da água. Quanto maior a dissociação de íons $\mathrm{Na}^{+}$e $\mathrm{Cl}^{-}$e um alto teor de sólidos dissolvidos em água, maior é a condutividade desta. Os valores obtidos para a salinidade e TDS se relacionam com a condutividade, ou seja, o aumento na concentração de íons em solução reflete em aumento da condutividade (SILVA, 2007).

A água pode ser classificada segundo a sua dureza em: mole ou branda $(<50 \mathrm{mg} / \mathrm{L} \mathrm{de}$ $\mathrm{CaCO}_{3}$ ); dureza moderada (entre 50 e $150 \mathrm{mg} / \mathrm{L}$ de $\mathrm{CaCO}_{3}$ ); dura (entre 150 e $300 \mathrm{mg} / \mathrm{L}$ de $\mathrm{CaCO}_{3}$ )e muito dura (> $300 \mathrm{mg} / \mathrm{L}$ de $\mathrm{CaCO}_{3}$ ). De acordo com a legislação, o teor de $\mathrm{CaCO}_{3}$ estabelecido para dureza em água potável é de $500 \mathrm{mg} / \mathrm{L}$ de $\mathrm{CaCO}_{3}$. Considerando os valores, tabela 1, obtidos para os nove pontos na seca e na chuva, a água do lago Bonsucesso é considerada mole ou branda, ou seja, possui alcalinidade menor que $50 \mathrm{mg} / \mathrm{L}$ de $\mathrm{CaCO}_{3}$ (BAIRD, 2002).

Com relação a TURB, a resolução CONAMA n 357/2005 estabelece o valor máximo de 100 UNT para águas de classe 3. Ao comparar os resultados obtidos para os nove pontos, todos se encontram dentro do permitido para águas naturais, ou seja, se enquadram na classe 3.

Segundo a resolução CONAMA n 357/2005, águas de classe 3 devem possuir fósforo total (P), para ambiente lótico e tributários de ambientes intermediários, igual a $0,15 \mathrm{mg} / \mathrm{L}$. De acordo com os valores obtidos, tabela 1 , todos os pontos apontaram valores superiores aos pré-estabelecidos pelo CONAMA. Embora ainda não ser observado o crescimento de algas no interior do lago Bonsucesso, os valores indicam um processo de eutrofização, fato este que poderá interferir na sobrevivência de espécies aquáticas, em especial os peixes. 


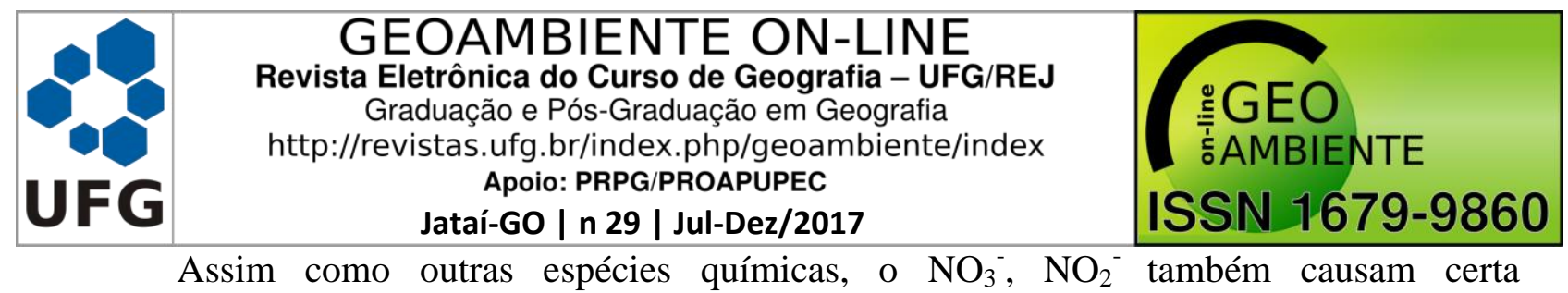

preocupação com o aumento nos níveis de concentração em águas naturais. De acordo com a literatura, o excesso de nitrato em água potável constitui um risco para a saúde, especialmente para os bebês que fazem uso de mamadeiras não esterilizadas. A presença de bactérias em mamadeiras pode reduzir o $\mathrm{NO}_{3}{ }^{-}, \mathrm{NO}_{2}^{-}$, que por sua vez combina-se com a hemoglobina, promovendo sua oxidação. Como consequência, haverá o impedindo da absorção e o transporte adequado de oxigênio para as células, causando assim, asfixia do bebê, uma doença conhecida com síndrome do "bebê azul" (BAIRD, 2002). Os valores estabelecidos pela resolução CONAMA no $n^{\circ} 357 / 2005$ para $\mathrm{NO}_{3}{ }^{-}, \mathrm{NO}_{2}{ }^{-}$são $10,0 \mathrm{mg} / \mathrm{L}$ e $1,0 \mathrm{mg} / \mathrm{L}$, respectivamente. Os dados obtidos, tabela 1, indicam a ausência dessas espécies na composição da água do lago Bonsucesso.

\section{1 - Parâmetros físico-químicos do Sedimento}

A análise do perfil físico-químico do sedimento é um parâmetro bastante importante para estudos que visam identificar possíveis efeitos negativos através das atividades antropogênicas. Os resultados obtidos foram apresentados na tabela 2 a seguir.

Tabela 2: Parâmetros físico-químicos do Sedimento

\begin{tabular}{llll}
\hline Pontos & PH & MO $(\%)$ & CTC \\
\hline 1 & 5,71 & $17,73 \%$ & 6,60 \\
2 & 4,82 & $3,73 \%$ & 2,20 \\
3 & 4,44 & $17,52 \%$ & 8,80 \\
4 & 4,76 & $24,34 \%$ & 6,60 \\
5 & 4,73 & $19,74 \%$ & 6,60 \\
6 & 4,51 & $24,89 \%$ & 6,60 \\
7 & 4,21 & $22,23 \%$ & 4,40 \\
8 & 4,53 & $26,65 \%$ & 4,40 \\
9 & 4,25 & $20,36 \%$ & 2,20 \\
\hline
\end{tabular}

Um teor de MO maior que $10 \%$ pode ser considerado um sedimento orgânico, ou seja, está havendo o acumulo de MO nesses locais (LIMA, 2013). A partir dos resultados obtidos, pode-se notar que os teores de MO variaram entre $3,73 \%$ e $26 \%$, sendo o ponto 2 o que apresentou um menor teor de MO e o ponto 8 o maior teor. A partir disso pode-se aferir que está havendo o acumulo de MO no lago Bonsucesso, sendo que em função da presença de vários grupos contendo oxigênio, essa MO auxilia na complexação de espécies metálicas (DIAS, 2009). 


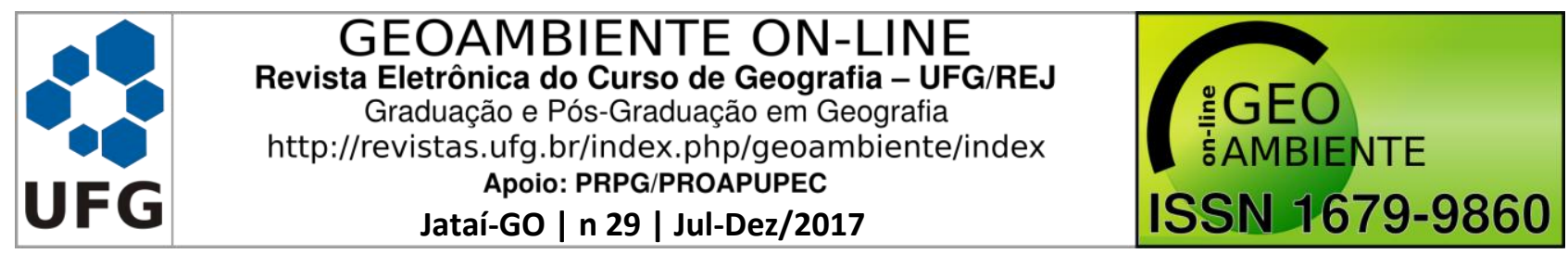

Com relação ao $\mathrm{pH}$ das amostras de sedimento, este apresentaram características ácidas em água deionizada e em solução de cloreto de cálcio. Este comportamento pode estar relacionado ao excesso de MO no lago Bonsucesso. De acordo com a literatura, a decomposição da MO leva à formação de ácido sulfúrico, aumentando assim a concentração de $\mathrm{H}^{+}$presente no sedimento, tendo como conseqüência a acidez observada no sedimento. $\mathrm{O}$ decréscimo de $\mathrm{pH}$ pode promover a solubilização de carbonatos e hidróxidos, modificando a dessorção de cátions metálicos complexados pela matéria orgânica. Neste caso, a dessorção ocorre devido à competição desses cátions com íons $\mathrm{H}^{+}$(MARGALEF, 1983).

Valores de CTC acima de 5 cmolc $/ \mathrm{kg}$, evidenciam uma alta capacidade de troca de cátions do solo e sedimento com o meio, trocando íons efetivamente e retendo uma maior quantidade de metais, em um valor de $\mathrm{pH}$ próximo ao seu valor natural. De acordo com a tabela 2, os pontos 2, 7, 8 e 9 estão abaixo deste valor, mostrando assim a alta capacidade dos demais pontos em realizar a troca de cátions. A alta capacidade de retenção de cátions também pode estar relacionada ao acumulo de matéria orgânica. Considera-se então que um alto valor de matéria orgânica presente no local maior é a capacidade que o sedimento tem em reter metais pesados (BAIRD, 2002).

\section{3 - Determinação de metais pesados em sedimento}

A caracterização química do sedimento com relação a concentração das substâncias poluentes em estudo (metais pesados) contidas na fração total da amostra, deve ser feita e comparada com a Resolução CONAMA 454/2012. Esta resolução dispõe de valores orientadores de qualidade do solo quanto à presença de substâncias químicas oriundas de atividades antropogênicas.

Todos os valores encontrados (Tabela 3) foram determinados levando-se em consideração os limites de detecção (LD) e de quantificação (LQ) do equipamento para cada metal. Já os desvios encontrados foram calculados considerando-se a faixa de $95 \%$ de confiança por meio da análise do teste $t$ de Student (LEITE, 2002). Com exceção do chumbo os demais metais foram encontrados nas amostras de sedimento. Sendo os metais Cádmio, Cromo, Cobre e Zinco apresentaram valores acima dos níveis 1 (Cromo, Cobre e Zinco) ou 2 (Cádmio e Zinco) permitidos pela resolução 454/2012 evidenciando o seu acúmulo no sedimento do lago.Deve ser destacado que o ponto 2 apresenta uma porcentagem de MO 


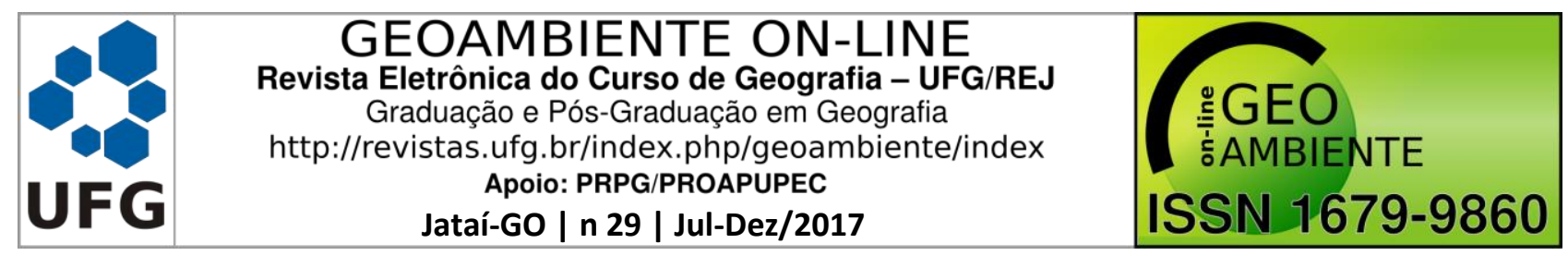

$(3,73 \%)$ muito pequena quando comparado aos demais pontos. A MO tem um papel muito importante no ambiente, pois na sua composição encontram-se as substâncias húmicas ( $\mathrm{SH})$. As substâncias apresentam característica macromolecular e que contêm inúmeros grupos funcionais que apresentam uma grande habilidade em complexar inúmeras espécies químicas, por exemplo, os metais pesados e agroquímicos.

A legislação brasileira não dispõe de limites máximos permitidos em sedimentos para os metais: Alumínio, Manganês e Ferro. Estes metais podem ser encontrados no ambiente a partir de processos naturais de formações de rochas, ou serem incrementados via antropogênica como processos industriais, utilização de fertilizantes, entre outros. Os valores elevados de concentração para estes metais também podem ser explicados devido ao carreamento de partículas de solo contendo Al, lembrando que este metal é característico de solos presentes na região de estudo.

Tabela 3 -Concentração $\left(\mathrm{mg} \cdot \mathrm{Kg}^{-1}\right)$ dos metais em estudo para as amostras de sedimento.

$\mathrm{Nd}=$ Não detectado

\begin{tabular}{|c|c|c|c|c|c|c|c|c|c|c|}
\hline Pontos & As & $\mathrm{Cd}$ & $\mathrm{Pb}$ & $\mathrm{Cr}$ & $\mathrm{Cu}$ & $\mathrm{Ni}$ & $\mathrm{Zn}$ & $\mathrm{Fe}$ & $\mathrm{Mn}$ & $\mathrm{Al}$ \\
\hline 1 & $\begin{array}{l}0,00 \\
\pm 0,591\end{array}$ & $\begin{array}{l}9,30 \\
\pm 1,411\end{array}$ & $\mathrm{Nd}$ & $\begin{array}{l}35,30 \\
\pm 7,878\end{array}$ & $\begin{array}{l}56,80 \\
\pm 26,443\end{array}$ & $\begin{array}{l}9,00 \\
\pm 0,602\end{array}$ & $\begin{array}{l}68,80 \\
\pm 11,515\end{array}$ & $\begin{array}{l}4013,50 \\
\pm 574,936\end{array}$ & $\begin{array}{l}231,30 \\
\pm 58,071\end{array}$ & $\begin{array}{l}2324,20 \\
\pm 1083,497\end{array}$ \\
\hline 2 & $\begin{array}{l}0,35 \\
\pm 0,591\end{array}$ & $\begin{array}{l}2,60 \\
\pm 1,411\end{array}$ & $\mathrm{Nd}$ & $\begin{array}{l}10,70 \\
\pm 7,878\end{array}$ & $\begin{array}{l}11,90 \\
\pm 26,443\end{array}$ & $\begin{array}{l}6,65 \\
\pm 0,602\end{array}$ & $\begin{array}{l}15,20 \\
\pm 11,515\end{array}$ & $\begin{array}{l}1204,30 \\
\pm 574,936\end{array}$ & $\begin{array}{l}115,70 \\
\pm 58,071\end{array}$ & $\begin{array}{l}7100,40 \\
\pm 1083,497\end{array}$ \\
\hline 3 & $\begin{array}{l}2,25 \\
\pm 0,591\end{array}$ & $\begin{array}{l}7,75 \\
\pm 1,411\end{array}$ & $\mathrm{Nd}$ & $\begin{array}{l}41,70 \\
\pm 7,878\end{array}$ & $\begin{array}{l}94,40 \\
\pm 26,443\end{array}$ & $\begin{array}{l}8,95 \\
\pm 0,602\end{array}$ & $\begin{array}{l}35,90 \\
\pm 11,515\end{array}$ & $\begin{array}{l}3148,60 \\
\pm 574,936\end{array}$ & $\begin{array}{l}244,40 \\
\pm 58,071\end{array}$ & $\begin{array}{l}2921,80 \\
\pm 1083,497\end{array}$ \\
\hline 4 & $\begin{array}{l}1,75 \\
\pm 0,591\end{array}$ & $\begin{array}{l}6,00 \\
\pm 1,411\end{array}$ & $\mathrm{Nd}$ & $\begin{array}{l}40,90 \\
\pm 7,878\end{array}$ & $\begin{array}{l}93,10 \\
\pm 26,443\end{array}$ & $\begin{array}{l}7,70 \\
\pm 0,602\end{array}$ & $\begin{array}{l}23,90 \\
\pm 11,515\end{array}$ & $\begin{array}{l}2505,40 \\
\pm 574,936\end{array}$ & $\begin{array}{l}235,10 \\
\pm 58,071\end{array}$ & $\begin{array}{l}3060,50 \\
\pm 1083,497\end{array}$ \\
\hline 5 & $\begin{array}{l}0,80 \\
\pm 0,591\end{array}$ & $\begin{array}{l}6,35 \\
\pm 1,411\end{array}$ & $\mathrm{Nd}$ & $\begin{array}{l}41,80 \\
\pm 7,878\end{array}$ & $\begin{array}{l}84,40 \\
\pm 26,443\end{array}$ & $\begin{array}{l}7,65 \\
\pm 0,602\end{array}$ & $\begin{array}{l}29,50 \\
\pm 11,515\end{array}$ & $\begin{array}{l}2679,79 \\
\pm 574,936\end{array}$ & $\begin{array}{l}339,00 \\
\pm 58,071\end{array}$ & $\begin{array}{l}2957,70 \\
\pm 1083,497\end{array}$ \\
\hline 6 & $\begin{array}{l}1,95 \\
\pm 0,591\end{array}$ & $\begin{array}{l}5,70 \\
\pm 1,411\end{array}$ & $\mathrm{Nd}$ & $\begin{array}{l}44,05 \\
\pm 7,878\end{array}$ & $\begin{array}{l}95,90 \\
\pm 26,443\end{array}$ & $\begin{array}{l}7,70 \\
\pm 0,602\end{array}$ & $\begin{array}{l}36,00 \\
\pm 11,515\end{array}$ & $\begin{array}{l}2661,70 \\
\pm 574,936\end{array}$ & $\begin{array}{l}150,20 \\
\pm 58,071\end{array}$ & $\begin{array}{l}3236,10 \\
\pm 1083,497\end{array}$ \\
\hline 7 & $\begin{array}{l}1,55 \\
\pm 0,591\end{array}$ & $\begin{array}{l}6,85 \\
\pm 1,411\end{array}$ & $\mathrm{Nd}$ & $\begin{array}{l}40,50 \\
\pm 7,878\end{array}$ & $\begin{array}{l}80,80 \\
\pm 26,443\end{array}$ & $\begin{array}{l}7,25 \\
\pm 0,602\end{array}$ & $\begin{array}{l}31,00 \\
\pm 11,515\end{array}$ & $\begin{array}{l}2801,20 \\
\pm 574,936\end{array}$ & $\begin{array}{l}146,80 \\
\pm 58,071\end{array}$ & $\begin{array}{l}2876,30 \\
\pm 1083,497\end{array}$ \\
\hline 8 & $\begin{array}{l}1,85 \\
\pm 0,591\end{array}$ & $\begin{array}{l}5,80 \\
\pm 1,411\end{array}$ & $\mathrm{Nd}$ & $\begin{array}{l}41,15 \\
\pm 7,878\end{array}$ & $\begin{array}{l}106,00 \\
\pm 26,443\end{array}$ & $\begin{array}{l}7,45 \\
\pm 0,602\end{array}$ & $\begin{array}{l}44,50 \\
\pm 11,515\end{array}$ & $\begin{array}{l}2475,30 \\
\pm 574,936\end{array}$ & $\begin{array}{l}201,10 \\
\pm 58,071\end{array}$ & $\begin{array}{l}3157,20 \\
\pm 1083,497\end{array}$ \\
\hline 9 & $\begin{array}{l}1,25 \\
\pm 0,591\end{array}$ & $\begin{array}{l}5,15 \\
\pm 1,411\end{array}$ & $\mathrm{Nd}$ & $\begin{array}{l}39,70 \\
\pm 7,878\end{array}$ & $\begin{array}{l}136,00 \\
\pm 26,443\end{array}$ & $\begin{array}{l}7,15 \\
\pm 0,602\end{array}$ & $\begin{array}{l}37,20 \\
\pm 11,515\end{array}$ & $\begin{array}{l}2196,70 \\
\pm 574,936\end{array}$ & $\begin{array}{l}100,60 \\
\pm 58,071\end{array}$ & $\begin{array}{l}3018,40 \\
\pm 1083,497\end{array}$ \\
\hline
\end{tabular}






3.4 - Determinação de metais pesados nas águas do lago Bonsucesso

Os padrões de qualidade da água doce de classe 3 para metais pesados em água são definidos pela Resolução CONAMA n 357/2005 onde estabelece os valores máximos para os parâmetros inorgânicos analisados, os quais possuem os seguintes limites máximos permitidos (Tabela 4).

Tabela 4: Valores limites permitidos de metais em água (mg.L $\left.\mathrm{L}^{-1}\right)$

\begin{tabular}{llllllllll}
\hline $\mathrm{Al}$ & $\mathrm{Cu}$ & $\mathrm{Fe}$ & $\mathrm{Mn}$ & $\mathrm{Zn}$ & $\mathrm{Ni}$ & $\mathrm{Cd}$ & $\mathrm{Cr}$ & $\mathrm{As}$ & $\mathrm{Mg}$ \\
\hline 0,2 & 0,013 & 5,0 & 0,5 & 5,0 & 0,025 & 0,01 & 0,05 & 0,033 & 0,002 \\
\hline
\end{tabular}

De acordo com os dados obtidos para o período seco (Tabela 5), todos os pontos avaliados apresentaram concentração de metais pesados em água inferiores ao limite de quantificação da técnica de ICP-OES utilizada. A ausência dos metais estudados no período de seca pode ser explicado em função do período de coleta, em que a ausência de chuva impede o carreamento de partículas do solo contendo espécies metálicas diretamente no corpo hídrico.

Tabela 5 - Concentração $\left(m g . L^{-1}\right)$ de metais pesados obtidos nas amostras de água no período de chuva.

\begin{tabular}{lllllllllll}
\hline Pontos & $\mathrm{Al}$ & $\mathrm{Cu}$ & $\mathrm{Fe}$ & $\mathrm{Mn}$ & $\mathrm{Zn}$ & $\mathrm{Ni}$ & $\mathrm{Cd}$ & $\mathrm{Cr}$ & $\mathrm{As}$ & $\mathrm{Hg}$ \\
\hline 1 & 0,63 & 0,02 & 0,53 & & 0,00 & $\mathrm{Nd}$ & $\mathrm{Nd}$ & $\mathrm{Nd}$ & 0,01 & 0,01 \\
& $\pm 0,0684$ & $\pm 0,0033$ & $\pm 0,1811$ & $\mathrm{ND}$ & $\pm 0,1555$ & & & & $\pm 0,0038$ & $\pm 0,0033$ \\
2 & 0,67 & 0,02 & 0,43 & & 0,04 & $\mathrm{Nd}$ & $\mathrm{Nd}$ & $\mathrm{Nd}$ & 0,00 & 0,00 \\
& $\pm 0,0684$ & $\pm 0,0033$ & $\pm 0,1811$ & $\mathrm{ND}$ & $\pm 0,1555$ & & & & $\pm 0,0038$ & $\pm 0,0033$ \\
3 & 0,50 & 0,02 & 0,34 & & 0,03 & $\mathrm{Nd}$ & $\mathrm{Nd}$ & $\mathrm{Nd}$ & 0,00 & 0,00 \\
& $\pm 0,0684$ & $\pm 0,0033$ & $\pm 0,1811$ & $\mathrm{ND}$ & $\pm 0,1555$ & & & & $\pm 0,0038$ & $\pm 0,0033$ \\
4 & 0,58 & 0,02 & 0,75 & & 0,63 & $\mathrm{Nd}$ & $\mathrm{Nd}$ & $\mathrm{Nd}$ & 0,00 & 0,00 \\
& $\pm 0,0684$ & $\pm 0,0033$ & $\pm 0,1811$ & $\mathrm{ND}$ & $\pm 0,1555$ & & & & $\pm 0,0038$ & $\pm 0,0033$ \\
5 & 0,44 & 0,02 & 0,28 & & 0,02 & $\mathrm{Nd}$ & $\mathrm{Nd}$ & $\mathrm{Nd}$ & 0,00 & 0,00 \\
& $\pm 0,0684$ & $\pm 0,0033$ & $\pm 0,1811$ & $\mathrm{ND}$ & $\pm 0,1555$ & & & & $\pm 0,0038$ & $\pm 0,0033$ \\
6 & 0,45 & 0,02 & 0,42 & & 0,03 & $\mathrm{Nd}$ & $\mathrm{Nd}$ & $\mathrm{Nd}$ & 0,01 & 0,01 \\
& $\pm 0,0684$ & $\pm 0,0033$ & $\pm 0,1811$ & $\mathrm{ND}$ & $\pm 0,1555$ & & & & $\pm 0,0038$ & $\pm 0,0033$ \\
7 & 0,61 & 0,01 & 0,40 & & 0,03 & $\mathrm{Nd}$ & $\mathrm{Nd}$ & $\mathrm{Nd}$ & 0,00 & 0,00 \\
& $\pm 0,0684$ & $\pm 0,0033$ & $\pm 0,1811$ & $\mathrm{ND}$ & $\pm 0,1555$ & & & & $\pm 0,0038$ & $\pm 0,0033$ \\
8 & 0,49 & 0,01 & 1,01 & & 0,02 & $\mathrm{Nd}$ & $\mathrm{Nd}$ & $\mathrm{Nd}$ & 0,01 & 0,00 \\
& $\pm 0,0684$ & $\pm 0,0033$ & $\pm 0,1811$ & $\mathrm{ND}$ & $\pm 0,1555$ & & & & $\pm 0,0038$ & $\pm 0,0033$ \\
9 & 0,44 & 0,02 & 0,34 & & 0,02 & $\mathrm{Nd}$ & $\mathrm{Nd}$ & $\mathrm{Nd}$ & 0,00 & 0,00 \\
& $\pm 0,0684$ & $\pm 0,0033$ & $\pm 0,1811$ & $\mathrm{ND}$ & $\pm 0,1555$ & & & & $\pm 0,0038$ & $\pm 0,0033$ \\
\hline
\end{tabular}

$\mathrm{Nd}=$ Não detectado

Os metais Ferro, Mangânes, Zinco, Níquel, Cádmio e Cromo apresentaram concentrações em amostras de água abaixo do valor limite máximo estabelecido pela 


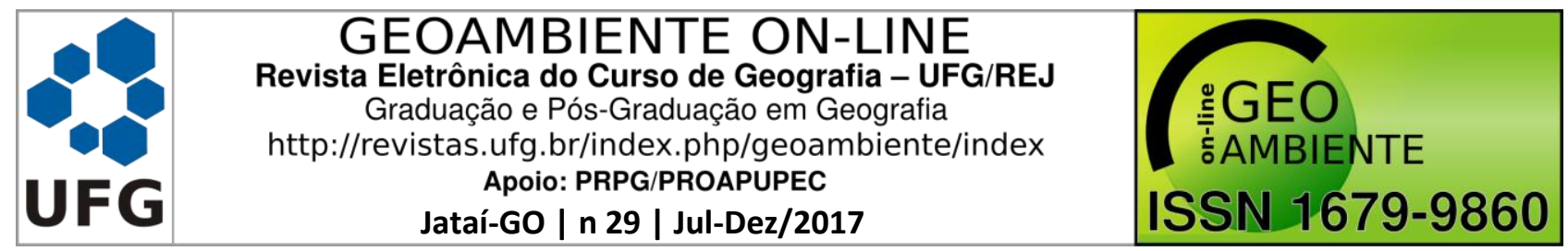

Resolução CONAMA 357/2005.Já os metais Alumínio e Cobre apresentaram concentrações acima do permitido pela legislação em todos os pontos de amostragem, Os metais Arsênio e Mercúrio apresentaram valores superiores ao estabelecido pela Resolução CONAMA 357/2005 nos pontos 1,6, 8 e 1, 6, respectivamente. A presença destes metais no período de chuva pode ser explicada em função do carreamento pela água da chuva, levando consigo poluentes oriundos de atividades agrícolas. É importante e necessário relatar que a presença dessas espécies químicas podem causar efeitos adversos à bióta e aos seres humanos frequentadores do lago Bonsucesso, especialmente para atividades de lazer como a pesca. Neste sentido, torna-se necessário um monitoramento constante das águas do lago Bonsucesso.

\section{5 - Análise infravermelho da substância húmica (SH)}

A figura 3 a seguir apresenta o espectro de infravermelho do $\mathrm{AH}$ extraído do sedimento do lago Bonsucesso.

Figura 3 -Espectro de infravermelho do AH extraído do sedimento

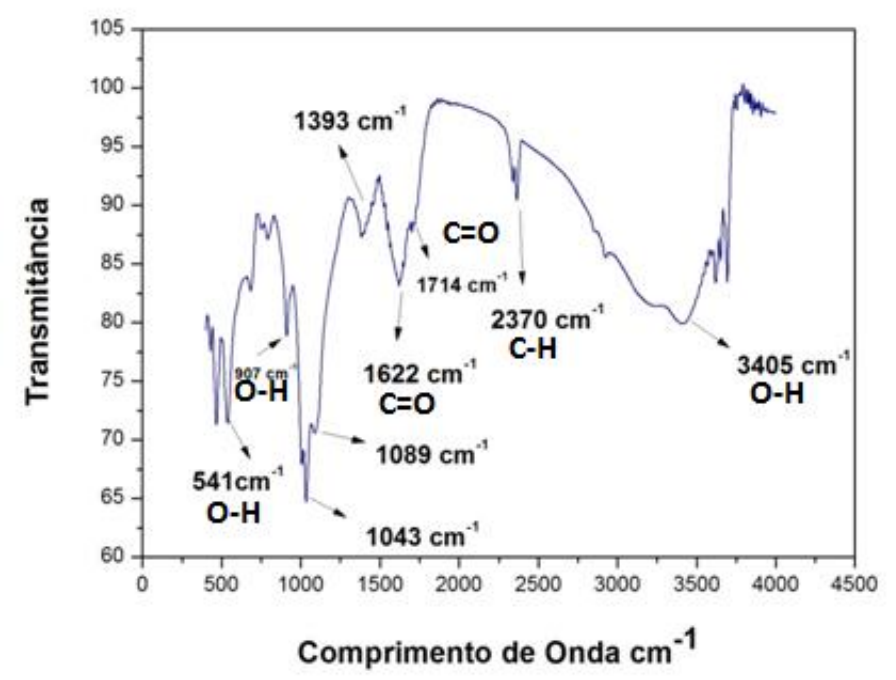

De acordo com a literatura e a partir da análise infravermelho, pode-se inferir que o AH possui vários grupos funcionais como carboxilas e hidroxilas (ROCHA, 2003). Estes grupos têm como característica reter íons metálicos de vários modos, sendo, por exemplo: adsorção, atração eletrostática ou quelação. Embora na presente pesquisa não tenham sido realizados estudos de adsorção com os metais identificados, a presença dos mesmos em altas 


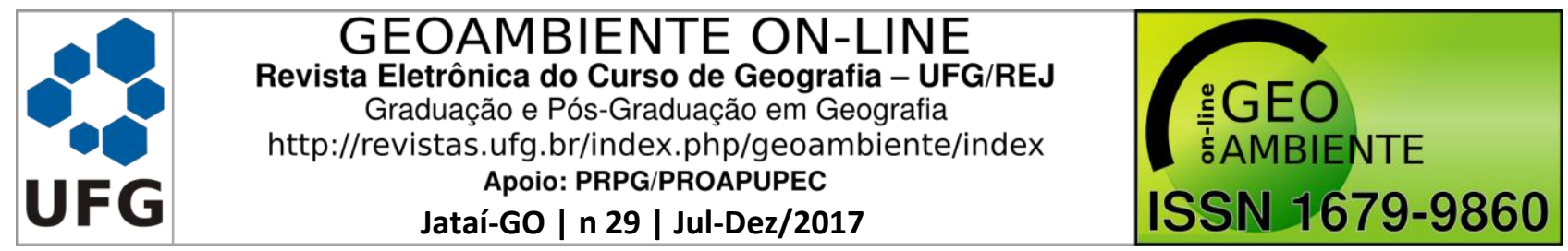

concentrações no sedimento pode ser atribuída pela presença de MO, especialmente pelo $\mathrm{AH}$ (STEVENSON, 1994).

\section{4 - CONCLUSÃO}

- Os resultados apresentados neste trabalho indicam que as atividades antrópicas realizadas nas proximidades do lago Bonsucesso, tais como atividades agrícolas que utilizam agrotóxicos e fertilizantes, poderá afetar com efeitos negativos a biota do local. O perfil do sedimento do lago indicou um sedimento orgânico, ou seja, com teor de matéria orgânica acima de $10 \%$, o que indica uma maior facilidade para a complexação de poluentes como os metais pesados. De maneira geral, o pH das amostras de sedimento apresentaram características ácidas, o que pode contribuir para a liberação de metais pesados complexados na MO presente. De acordo com a literatura, valores acima de $5 \mathrm{cmolc} / \mathrm{Kg}$ indicam uma alta capacidade que o sedimento tem de troca catiônica, os pontos 2,7,8 e 9 estão abaixo deste valor, indicando uma capacidade de troca com cátions metálicos.

- As análises de metais pesados no sedimento revelaram a presença dos metais Cádmio, Cromo, Cobre e Zinco acima dos níveis 1 ou 2 da resolução CONAMA 454/2012, evidenciando o seu acúmulo no sedimento do lago.

- As análises de metais pesados nas águas do lago Bonsucesso revelaram a presença dos metais Arsênio e Mercúrio acima dos valores estabelecidos pela resolução CONAMA 357/2005. Os resultados indicam uma grande probabilidade de efeitos adversos à biota e aos seres humanos, o que torna necessário um monitoramento constante das águas do lago Bonsucesso. Além dos metais pesados é necessário realizar estudos para a avaliação de resíduos de pesticidas no sedimento e nas águas do lago Bonsucesso.

\section{5 - REFERÊNCIAS BIBLIOGRÁFICAS}

ALVES, R.I. S.; TONANI, K. A. A.; NIKAIDO, M.; CARDOSO, O.O.; TREVILATO, T. M. B; SEGURA-MUÑOZ, S. I. Avaliação das concentrações de metais pesados em águas superficiais e sedimentos do Córrego Monte Alegre e afluentes, Ribeirão Preto, SP, Brasil. Ambi-água, Taubaté, v. 5, n. 3, p. 122-132, 2010. 


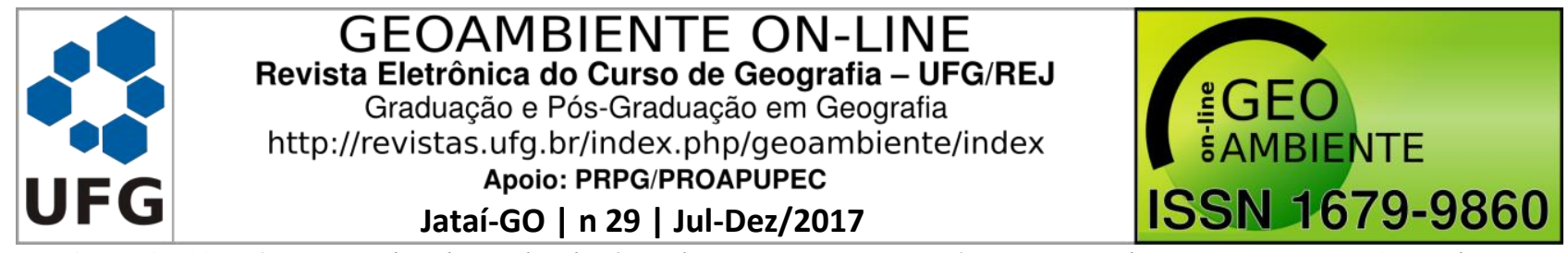

APHA (1998). Standard methods for the examination of water and wastewater - American

Public Health Association, American Water Works Association, Water Environmental Federation, $20^{\text {th }}$ ed. Washington.

ARIAS, A. R. L; BUS, D.F; ALBURQUERQUE, C; INÁCIO, A.L; FREIRE, M.M; EGLER,M; MUGNAI, R; BAPTISTA, D.F. Utilização de bioindicadores na avaliação de impacto e no monitoramento da contaminação de rios e córregos por agrotóxicos. Ciência \& Saúde Coletiva, p. 61-72, 2007.

BAIRD, C. Química Ambiental. 2a edição. Porto Alegre: Bookman. 622p. 2002.

DIAS, O. B.; SILVA, A.C.; SOARES, B. M. E.; BETTIOL, W.; GUERREIRO, C. M.; BLIZÁRIO, H, M.; Infravermelho na caracterização de ácidos húmicos de latossolo sob efeito do uso contínuo de lodo de esgoto. Revista. Brasileira de Ciências do Solo, n. 33, p.885894, 2009.

DUARTE, R.P.S.; PASQUAL, A. Avaliação do cádmio $(\mathrm{Cd})$, chumbo $(\mathrm{Pb})$, níquel $(\mathrm{Ni})$ e zinco (Zn) em solos, plantas e cabelos humanos. Energia na Agricultura, Botucatu, v.15, n.1, p.46-58, 2000.

FILIZOLA, H.F; GOMES, M.A.F; SOUZA, M.D. Manual de Procedimentos de Coleta de Amostras em Áreas Agrícolas para Análise da Qualidade Ambiental: Solo, Água e Sedimentos. Ed. Embrapa Meio Ambiente, 2006.

JACKSON, M.L. Soil Chemical Analysis, New Delhi, India Privatte Limited, 1967.

KASPERA, D, FORSBERGA, B.R, ALMEIDAB, R, BASTOSC. W.R, MALMD, O. Metodologias de coleta, preservação e armazenamento de amostras de água para análise de mercúrio - uma revisão, Química Nova, v.38, n.3, p. 410-418, 2015.

LEITE, F. Validação em análise química. $4^{0}$ ed., Campinas, Editora Átomo, 2002.

LIMA, P. D. Avaliação da contaminação por metais pesados na água e nos peixes da bacia do rio Cassiporé, estado do Amapá, Amazônia, Brasil. 2013. Dissertação (Mestrado) Fundação Universidade Federal do Amapá, Programa de Pós Graduação em Biodiversidade Tropical, 2013.

MARGALEF, R. Limnologia. Barcelona, Omega, 1983. 


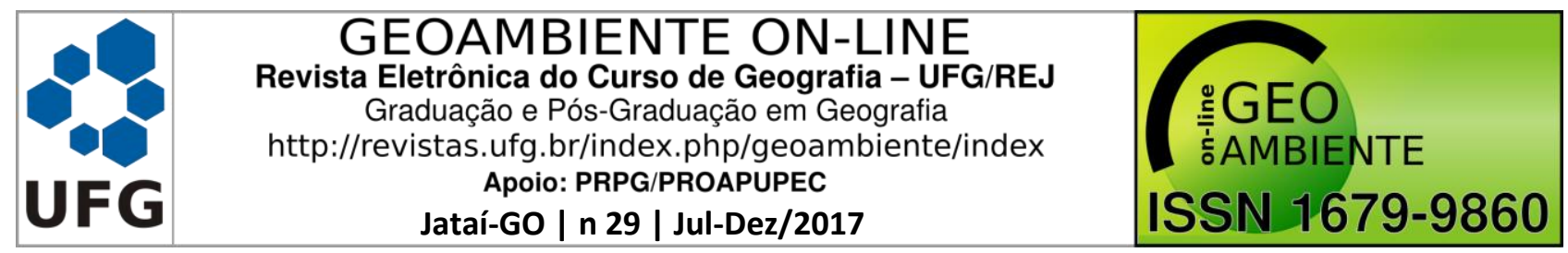

MOURAL, S. L.; BRAGA, O. J. R.; SIQUEIRA, R. E.; KOPP, A. K. O papel do sedimento na qualidade da água de abastecimento urbano: Uma revisão de trabalhos publicados entre 2001 e 2011. REEC - Revista Eletrônica de Engenharia Civil, vol 7, n.1, 2013.

RESOLUÇÃO CONAMA N 454, DE $1^{\circ}$ DE NOVEMBRO DE 2012. Disponível em: <http://www.icmbio.gov.br/cepsul/images/stories/legislacao/Resolucao/2012/res_conama_45 4_2012_materialserdragadoemaguasjurisdicionaisbrasileiras.pdf> Acessado: 28/02/2017.

RESOLUÇÃO CONAMA N $\mathrm{N}^{\mathrm{O}}$ 357, DE 17 DE MARÇO DE 2005 Disponível em <http://www.mma.gov.br/port/conama/legiabre.cfm?codlegi=459> Acessado: 28/02/2017.

ROCHA, J.C; ROSA, A.H. Substâncias húmicas aquáticas: interações com espécies metálicas. São Paulo, Editora UNESP, 2003, 120p.

ROSA, A.H.; ROCHA, J.C.; FURLAN, M. Substâncias húmicas de turfa: estudo dos parâmetros que influenciam no processo de extração alcalina. Química Nova, v.23 (4), p. 472-476, 2000.

SILVA, A. S. Avaliação do assoreamento do lago Bonsucesso, Jataí - GO. 2007. Dissertação (Mestrado em Geologia Ambiental, ao Setor de Ciências da Terra) - Curso de Pós-Graduação, Geologia da Universidade Federal do Paraná (UFPR), 2007.

STEVEnSON, F. J. Humus Chemistry: Genesis, Composition, Reactions. $2^{\mathrm{a}}$ ed. New York: John Wiley, 1994. 